$09 ; 15$

\title{
Сканирующая ближнепольная оптическая наноспектрофотометрия: метод наномасштабного измерения спектров поглощения единичных нанообъектов
}

\author{
(C) К.Е. Мочалов ${ }^{1}$, Д.О. Соловьева ${ }^{1}$, И.С. Васкан ${ }^{1-3}$, И.Р. Набиев ${ }^{2,4, \uparrow}$ \\ ${ }^{1}$ Лаборатория биофизики, Институт биоорганической химии им. акад. М.М. Шемякина и Ю.А. Овчинникова РАН, Москва, \\ Россия \\ 2 Лаборатория нанобиоинженерии, Национальный исследовательский ядерный университет „МИФИ“ (Московский \\ инженерно-физический институт), Москва, Россия \\ ${ }^{3}$ Московский фризико-технический институт (Государственный университет), Долгопрудный, Московская обл., Россия \\ ${ }^{4}$ Лаборатория по исследованиям в области нанонаук, Университет г. Реймса, Шампань-Арденн, Реймс, Франция \\ ฯ E-mail: igor.nabiev@gmail.com
}

Поступило в Редакцию 7 ноября 2018 г.

В окончательной редакции 7 ноября 2018 г.

Принято к публикации 21 ноября 2018 г.

Разработана экспериментальная методика наномасштабного измерения спектров поглощения единичных нанообъектов на основе использования сканирующей ближнепольной оптической микроспектроскопии СБОМ-наноспектрофотометрия. Основным отличием разработанной методики является нанесение образцов на покровные стекла с последующим введением в них возбуждающего излучения в режиме полного внутреннего отражения. Предложенный подход позволяет существенно увеличить количество исследуемых образцов, а также дает возможность проводить исследования с одновременным использованием других оптических методов анализа. Разработанная методика применена для исследования единичных плазмонных наночастиц и их комплексов с красителем родамин 6Ж.

DOI: 10.21883/PJTF.2019.04.47330.17581

Разработка методик наномасштабного измерения спектров поглощения единичных нанообъектов или структур, составленных из подобных объектов, является актуальной задачей на протяжении всей истории развития нанотехнологии, в том числе аппаратных средств оптического и спектрального наномасштабного анализа [1]. Одной из наиболее привлекательных областей применения наномасштабного измерения спектров поглощения (наноспектрофотометрии) является исследование спектрального вида оптического поглощения наногетероструктур, находящихся в так называемом гибридном состоянии „свет-вещество“ за счет образования сильной фотон-экситонной связи [2]. В частности, особый интерес представляют структуры, где на плазмонные наночастицы, являющиеся оптическим резонатором, адсорбированы органические молекулы, обладающие сильным дипольным моментом экситонного перехода [3,4].

Очевидно, что одним из наиболее перспективных подходов для создания методики наноспектрофотометрии является использование методов сканирующей ближнепольной оптической микроспектроскопии (СБОМ), позволяющей одновременно исследовать оптические (спектральные) и морфологические свойства вещества [5]. Однако, несмотря на почти тридцатилетнюю историю активного развития СБОМ, тематике так называемого „white-light NSOM“ (NSOM - near-field scanning optical microscopy), т. е. СБОМ в режиме спектрального измерения проходящего через образец света (СБОМ-наноспектрофотометрии), посвящено чрез- вычайно мало работ - на уровне единиц в десятилетие [6-9]. Это связано с отсутствием на протяжении долгого времени широкополосных источников света достаточной для детекции СБОМ-зондом мощности [6]. Единственным инструментальным решением для реализации СБОМ-наноспектрофотометрии было использование перестраиваемых лазеров. Для получения данных с использованием такого подхода выполнялось построение последовательности СБОМ-изображений в фиксированных длинах волн с последующим сравнением их между собой $[7,8]$, что требует чрезвычайно долгого времени проведения эксперимента. Значительный прогресс был достигнут с увеличением доступности суперконтинуумных „белых“ лазеров [9], в [10] продемонстрировано их бесспорное преимущество для реализации СБОМ-наноспектрофотометрии. Однако, несмотря на несомненный вклад работы [10] в развитие методики СБОМ-наноспектрофотометрии, именно в работах $[7,8]$ разработаны и описаны основные технические принципы СБОМ-наноспектрофотометрии:

1) использование неметаллизированного волоконного СБОМ-зонда;

2) использование поверхности призмы полного внутреннего отражения (ПВО) для нанесения исследуемого образца.

В целом использование призм ПВО является известным решением для СБОМ. Основное их достоинство состоит в отсутствии проходящего сквозь всю систему и не взаимодействующего с образцом света, что значительно 


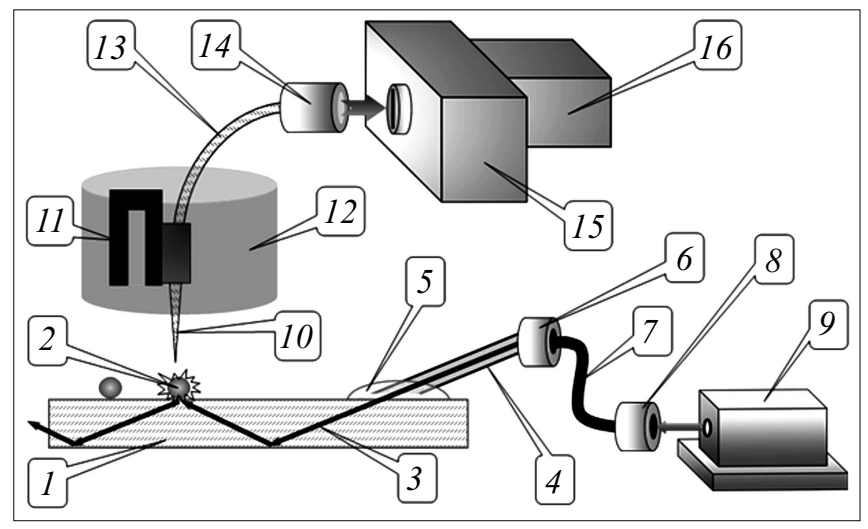

Рис. 1. Схема экспериментальной установки. 1 - покровное стекло; 2 - образец, нанесенный на покровное стекло; 3 лазерное излучение, распространяющееся в покровном стекле в режиме ПВО; 4 - металлическая трубка с впаянным волокном; 5 - капля глицерина; $6-$ узел оптического сопряжения многомодового волокна и металлической трубки с впаянным волокном; 7 - многомодовое волокно; $8-$ узел оптического сопряжения многомодового волокна и лазера; 9 - лазер; $10-$ ближнепольный волоконный зонд; 11 - кварцевый резонатор; 12 - сканирующая головка сканирующего зонондового микроскопа (СЗМ); 13 - одномодовое волокно зонда СЗМ; 14 система оптического сопряжения одномодового волокна зонда C3М и монохроматора; $15-$ монохроматор; $16-\mathrm{CCD}$.

повышает общее отношение сигнал/шум. В частности, в случае флуоресцентного сканирующего ближнепольного оптического микроскопа возбуждающее лазерное излучение проходит внутри призмы и почти не попадает в собирающий зонд. Еще большее значение имеет использование ПВО для СБОМ-наноспектрофотометрии, поскольку в отличие от флуоресцентных измерений в данном случае нет возможности спектрально разделить возбуждающее и провзаимодействовавшее с образцом излучение. При этом очевидно, что в случае СБОМ-наноспектрофотометрии без использования ПВО из-за чрезвычайно малого количества вещества и зачастую малых значений сечения взаимодействия доля регистрируемого в общем канале возбуждающего излучения будет существенно преобладать. Основными недостатками использования призм ПВО для нанесения исследуемых образцов являются их относительная дороговизна и крайнее неудобство для последующего использования подготовленных таким образом образцов в других измерительных методиках. Например, образцы, нанесенные на поверхность призмы ПВО, невозможно исследовать методами инвертированной оптической микроскопии.

В настоящей работе предлагается, на наш взгляд, наиболее универсальное и учитывающее весь прошлый опыт техническое решение для реализации СБОМ-наноспектрофотометрии. На рис. 1 приведена схема разработанной нами экспериментальной установки. Основным техническим новшеством данной схемы является применение недавно разработанного подхода, основанного на возбуждении в режиме ПВО образцов, осажденных на поверхности стандартного покровного стекла 1 , который ранее был использован для метода флуоресцентной микроскопии полного внутреннего отражения [11]. В нашем случае исследуемым образцом являлись единичные серебряные наночастицы (НЧ) 2, нанесенные на поверхность покровного стекла методом спин-коатинга. Лазерное излучение 3 , распространяющееся в покровном стекле в режиме ПВО, заводится с помощью специальной металлической трубки 4 с впаянным оптическим волокном, установленной под углом около $8^{\circ}$ к плоскости покровного стекла, при этом в области контакта металлической трубки и поверхностного стекла необходимо нанести каплю глицерина 5 для эффективного ввода излучения. Излучение заводится через многомодовое волокно $7 \mathrm{c}$ использованием системы сопряжения 8 с лазерами 9. В зависимости от задачи может использоваться либо узкополосный перестраиваемый лазер $\left(\mathrm{Ar}^{+}\right.$, ЛГН-519M, OАО Плазма), либо мощный суперконтинуумный лазер (SuperK FIANIUM с приставкой SuperK EXTEND-UV, NKT Photonics) для освещения образца в широкой спектральной области $(350-1000 \mathrm{~nm})$. Ближнепольное излучение, рассеянное образцом, собиралось с помощью неметаллизированного СБОМ-зонда 10 (MF001, ТипсНано). Сам сканирующий ближнепольный оптический микроскоп представляет собой часть уникальной научной установки (http:/ckp-rf.ru/usu/486825/ ЦКП ИБХ, грант Министерства образования и науки Российской Федерации № RFMEFI62117Х0018) [12], оборудованной СБОМ-головкой (SNOM-NTF, NT-MDT), монохроматором 15 (Shamrock 750, Andor) с прибором с зарядовой связью (CCD) 16 (DU971P-BV, Andor).

На рис. 2 приведены результаты СБОМ-наноспектрофотометрических измерений тестового образца единичных серебряных НЧ. На первом шаге измерительной процедуры выполнялось сканирование образца СБОМ-зондом в режиме „share force“ $(4 \times 4 \mu \mathrm{m}$, $256 \times 256$ точек) (рис. 2,a). Далее были выбраны три НЧ (указаны стрелками на рис. 2,a) для проведения СБОМ-наноспектрофотометрических измерений. Зонд удерживался в режиме обратной связи над каждой НЧ и с использованием суперконтинуумного лазера измерялся спектр пропускания в каждой точке с последующим вычитанием фона, записанного в свободной от НЧ области пространства (интегральная мощность $1 \mathrm{~W}$ и время накопления $1 \mathrm{~s})$. Результаты представлены на рис. 2, $b$. Полученные спектры поглощения единичных НЧ имеют отношение сигнал/шум не менее 2.5, максимумы поглощения центрированы на длины волн 398, 404 и $413 \mathrm{~nm}$ и имеют полуширины около 16, 18 и $23 \mathrm{~nm}$ для НЧ 1,2 и 3 соответственно, что вполне согласуется с теоретическими представлениями о поглощении единичных серебряных НЧ с диаметрами в районе $50-70 \mathrm{~nm}$. 

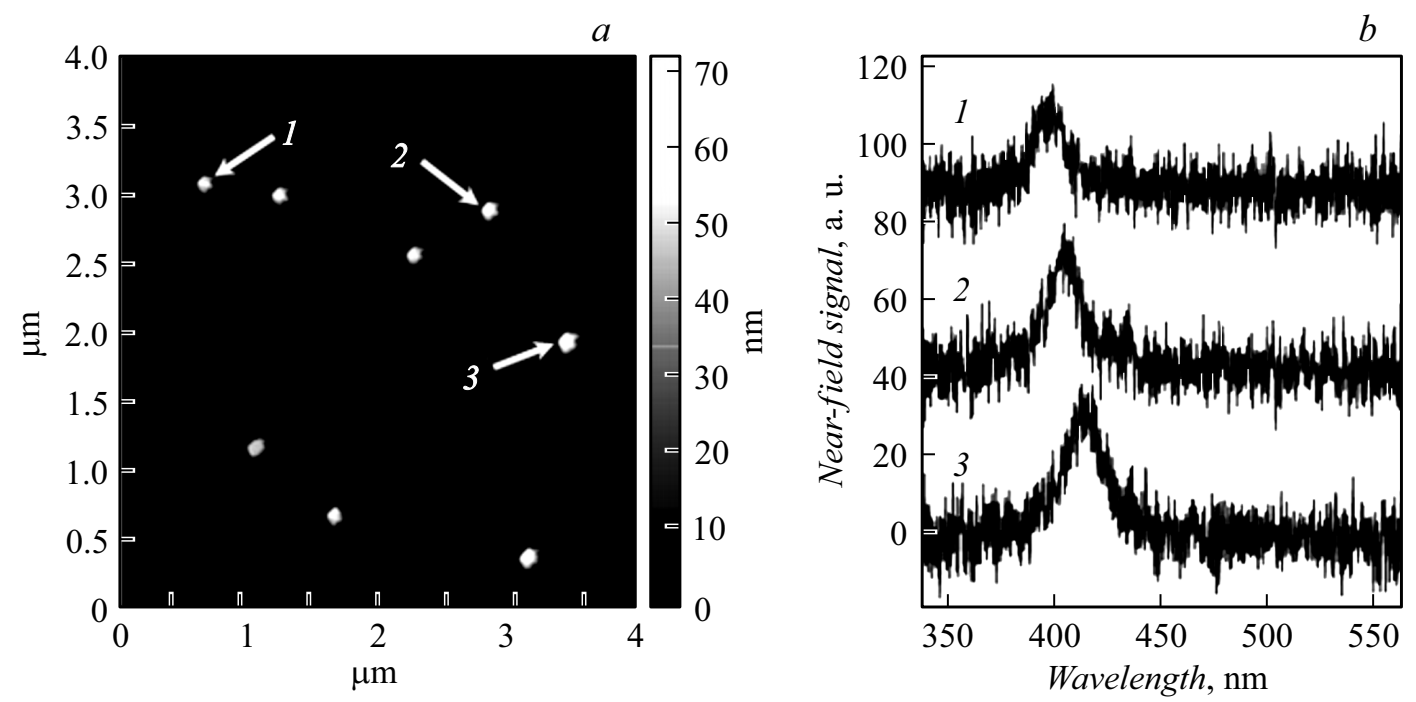

Рис. 2. Спектры ближнепольного поглощения единичных серебряных наночастиц. $a$ - изображение единичных наночастиц серебра, полученное с помощью атомно-силовой микроскопии, стрелками и цифрами указаны точки получения локального поглощения; $b$ - локальные спектры поглощения от единичных серебряных наночастиц $1-3$.
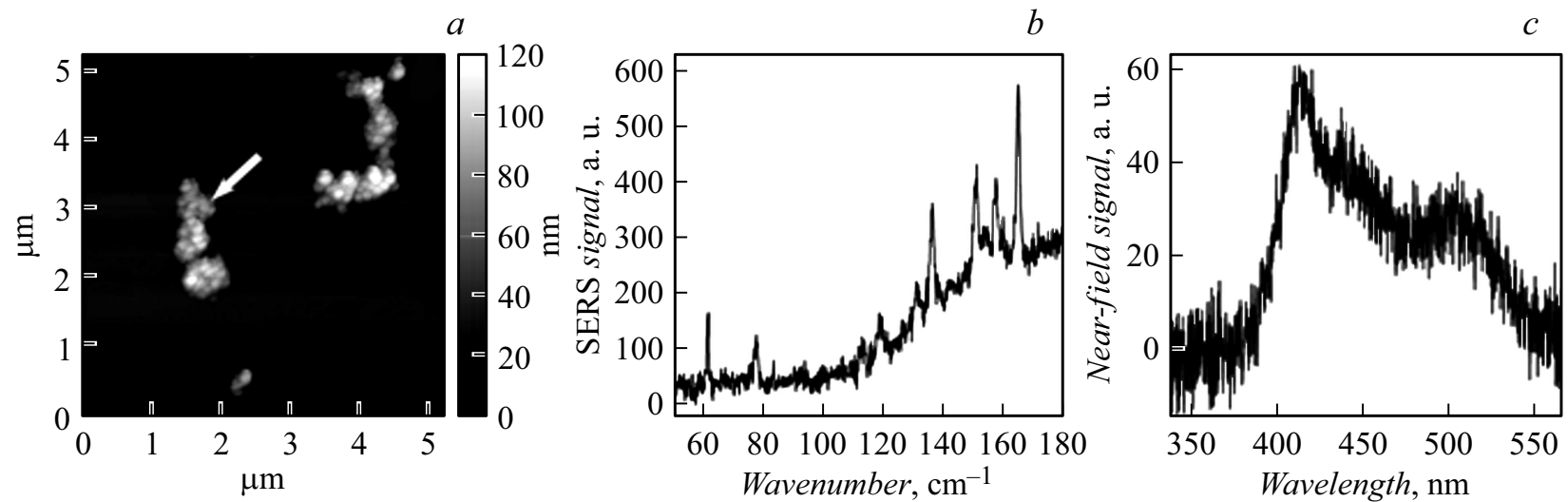

Рис. 3. Корреляционное измерение локальных спектров ГКР и поглощения. $a$ - изображение мицелл наночастиц серебра с адсорбированными молекулами Р6Ж, полученное с помощью атомно-силовой микроскопии, стрелкой указана точка получения локальных спектров ГКР и поглощения; $b$ - локальный спектр ГКР; $c$ - локальный спектр поглощения.

На рис. 3 приведен пример решения еще одной задачи, в которой демонстрируются возможности разработанной экспериментальной схемы. Нами были получены спектры поглощения в системе, состоящей из мицеллы агрегированных НЧ с адсорбированным красителем родамин 6Ж (Р6Ж). При этом спектр поглощения был получен непосредственно в „горячей точке“, где наблюдалось усиление комбинационного рассеяния (гигантское комбинационное рассеяние, ГКР). На первой стадии эксперимента покровное стекло с осажденными системами мицелла-НЧ/Р6Ж исследовалось методом конфокальной микроспектроскопии и были выявлены участки образца с существенными сигналами ГКР. Затем, не меняя положения образца, с помощью СБОМ-зонда мы получили топографические изображения мицелл $(5 \times 5 \mu \mathrm{m}$, $256 \times 256$ точек) (рис. 3,a). Далее с использованием возбуждения узкополосным лазером $(488 \mathrm{~nm}, 100 \mathrm{~mW})$, введенного в режиме ПВО, была обнаружена точка с приемлемым сигналом ГКР (рис. $3, b$ и точка, указанная стрелкой на рис. $3, a)$, полученным с временем накопления $3 \mathrm{~s}$. Заключительным шагом было получение спектра поглощения в данной точке способом, описанным выше (рис. 3,c). Спектр на рис. 3,c демонстрирует достаточно хорошее отношение сигнал/шум и представляет собой существенно неоднородно уширенные полосы, что свидетельствует о сильном взаимодействии НЧ в мицелле. Полученные данные требуют детального анализа и представляют значительный интерес для понимания механизмов возникновения эффекта ГКР.

В рамках настоящей работы нашей задачей была разработка экспериментальной схемы СБОМ-наноспектрофотометрии как с учетом всех ключевых достижений в данной области, так и с учетом требований максимальной гибкости и удешевления проведения эксперимен- 
тальных процедур. Последнее было достигнуто за счет введения нового элемента в схему СБОМ-наноспектрофотометрии - образцов, нанесенных на покровные стекла, с последующим введением в них излучения в режиме ПВО. Использование покровных стекол вместо призм ПВО не только существенно удешевляет эксперимент и, следовательно, увеличивает количество исследуемых образцов, но и не препятствует исследованию этих образцов целым рядом других методов.

Работа выполнена при поддержке Министерства науки и высшего образования РФ (государственный контракт № 16.1034.2017/ПЧ).

\section{Список литературы}

[1] Nano-optics and near-field optical microscopy / Eds A. Zayats, D. Richards. Boston: Artech House Publ., 2009. 361 p.

[2] Dovzhenko D.S., Ryabchuk S.V., Rakovich Yu.P., Nabiev I.R. // Nanoscale. 2018. V. 10. N 8. P. 3589-3605.

DOI: $10.1039 / \mathrm{C} 7 \mathrm{NR} 06917 \mathrm{~K}$

[3] Chikkaraddy R., Nijs B., Benz F., Barrow S.J., Scherman O.A., Rosta E., Demetriadou A., Fox P., Hess O., Baumberg J.J. // Nature. 2016. V. 535. N 7610. P. 127-130. DOI: 10.1038 /nature17974

[4] Zengin G., Johansson G., Johansson P., Antosiewicz T.J., Käll M., Shegai T. // Sci. Rep. 2013. V. 3. P. 3074. DOI: $10.1038 /$ srep03074

[5] Adams W., Sadatgol M., Güneya D.O. // AIP Adv. 2016. V. 6. P. 100701 (1-17). DOI: 10.1063/1.4964498

[6] Seidel J., Grafstrom S., Loppacher Ch., Trogisch S., Schlaphof F., Eng L.M. // Appl. Phys. Lett. 2001. V. 79. P. 2291-2293. DOI: $10.1063 / 1.1407862$

[7] Radko I.P., Sondergaard T., Bozhevolnyi S.I. // Opt. Express. 2006. V. 14. N 9. P. 4107-4114. DOI: 10.1364/OE.14.004107

[8] Biagi G., Holmgaard T., Skovsen E. // Opt. Express. 2013. V. 21. N 4. P. 4355-4360. DOI: 10.1364/OE.21.004355

[9] Supercontinuum generation in optical fibers / Eds J.M. Dudley, J.R. Taylor. Cambridge: Cambridge University Press, 2010. 419 p. DOI: 10.1017/CBO9780511750465

[10] Bouillard J.S., Vilain S., Dickson W., Zayats A.V. // Opt. Express. 2010. V. 18. N 16. P. 16513-16519. DOI: $10.1364 / \mathrm{OE} .18 .016513$

[11] Asanov A., Zepeda A., Vaca L // Sensors. 2012. V. 12. N 2. P. 1800-1815. DOI: $10.3390 / \mathrm{s} 120201800$

[12] Mochalov K.E., Chistyakov A.A., Solvyeva D.O., Mezin A.V., Oleinikov V.A., Molinari M., Agapov I.I., Nabiev I., Efimov A.E. // Ultramicroscopy. 2017. V. 182. P. 118-123. DOI: 10.1016/j.ultramic.2017.06.022 